\title{
LCMS-QTOF Determination of Lentinan-Like $\beta$-D-Glucan Content Isolated by Hot Water and Alkaline Solution from Tiger's Milk Mushroom, Termite Mushroom, and Selected Local Market Mushrooms
}

\author{
Nor Azreen Mohd Jamil, Norasfaliza Rahmad, \\ Noraswati Mohd Nor Rashid, Mohd Hafis Yuswan Mohd Yusoff, \\ Nur Syahidah Shaharuddin, and Norihan Mohd Saleh \\ Agro-Biotechnology Institute, P.O. Box 341, 43400 Serdang, Selangor, Malaysia \\ Correspondence should be addressed to Nor Azreen Mohd Jamil; arin2505@yahoo.com.my
}

Received 13 September 2013; Revised 2 November 2013; Accepted 2 November 2013

Academic Editor: Thierry Jouault

Copyright (C) 2013 Nor Azreen Mohd Jamil et al. This is an open access article distributed under the Creative Commons Attribution License, which permits unrestricted use, distribution, and reproduction in any medium, provided the original work is properly cited.

\begin{abstract}
Lentinan, 1152 Dalton $\beta$-D-glucan found in Shiitake Mushroom (Lentinus edodes), has been claimed to have anticancer and immunomodulatory activity. Several extraction methods have been used by researchers to isolate Lentinan including hot water and alkaline solution $(1.25 \mathrm{M} \mathrm{NaOH})$. In this study, hot water and alkaline solution $(1.25 \mathrm{M} \mathrm{NaOH})$ were used to extract the Lentinan-like $\beta$-D-glucan (1151 Dalton) from Tiger's Milk Mushroom, Termite Mushroom, and selected local market mushrooms. The isolated Lentinan-like $\beta$-D-glucan from both hot water and alkaline solution was analyzed by LCMS-QTOF. Commercial Lentinan standard from Lentinus edodes was used as a reference. The results showed significant differences on chromatogram patterns of Lentinanlike $\beta$-D-glucan between both extracts. The peak of Lentinan-like $\beta$-D-glucan was only found in isolated polysaccharide glucan of hot water extracts. The isolated polysaccharide glucans from Tiger's Milk Mushroom and Termite Mushroom were found to have $0.74 \pm 0.12 \mu \mathrm{g} / \mathrm{mg}$ and $0.53 \pm 0.07 \mu \mathrm{g} / \mathrm{mg}$ Lentinan-like $\beta$-D-glucan. Button Mushroom, Shiitake Mushroom, and Oyster Mushroom showed the presence of Lentinan-like $\beta$-D-glucan at $16.16 \pm 4.15 \mu \mathrm{g} / \mathrm{mg}, 0.22 \pm 0.04$, and $0.10 \pm 0.01 \mu \mathrm{g} / \mathrm{mg}$, respectively.
\end{abstract}

\section{Introduction}

Information on Tiger's Milk Mushroom and Termite Mushroom is still scanty and poor. Tiger's Milk Mushroom (Lignosus rhinocerus) has been found by Forest Research Institute of Malaysia (FRIM) as the most important medicinal mushroom used by the native [1]. This mushroom has been claimed to have therapeutic effects such as in treating cough, asthma, cancer, food poisoning, and as a general tonic [2]. While Termite Mushroom (Termitomyces heimii) is a wild seasonal mushroom that grows symbiotically with termite especially in rainy season. This mushroom was claimed to have very delicious taste and has extensively been used as human food [3]. It also has been used to treat lower blood pressure, rheumatism, kwashiorkor, obesity, and diarrhea [4].
A lot of potential bioactive compounds that are very useful for therapeutic purposes have been found in mushrooms including polysaccharides, polysaccharide peptide (protein complexes), proteoglycans, proteins, and triterpenoids [5-7]. $\beta$-D-glucan, a derivative of polysaccharide found in mushroom, has been recognized as a biological response modifier (BRM) since it possesses potent immune modulatory and anticancer activities $[8,9]$. The compound also has ability to improve human resistance against bacteria and viruses [10].

Lentinan is one of the most active 1,3/1,6- $\beta$-D-glucans found in Shiitake Mushroom (Lentinus edodes) that possesses immune modulator and anticancer activities. It is a branchedtype $\beta$-D-glucan with molecular weight of 1152 Dalton $[10,11]$. Lentinan has been widely used as an alternative medicine for potent anticancer and antiviral treatments and also has been 


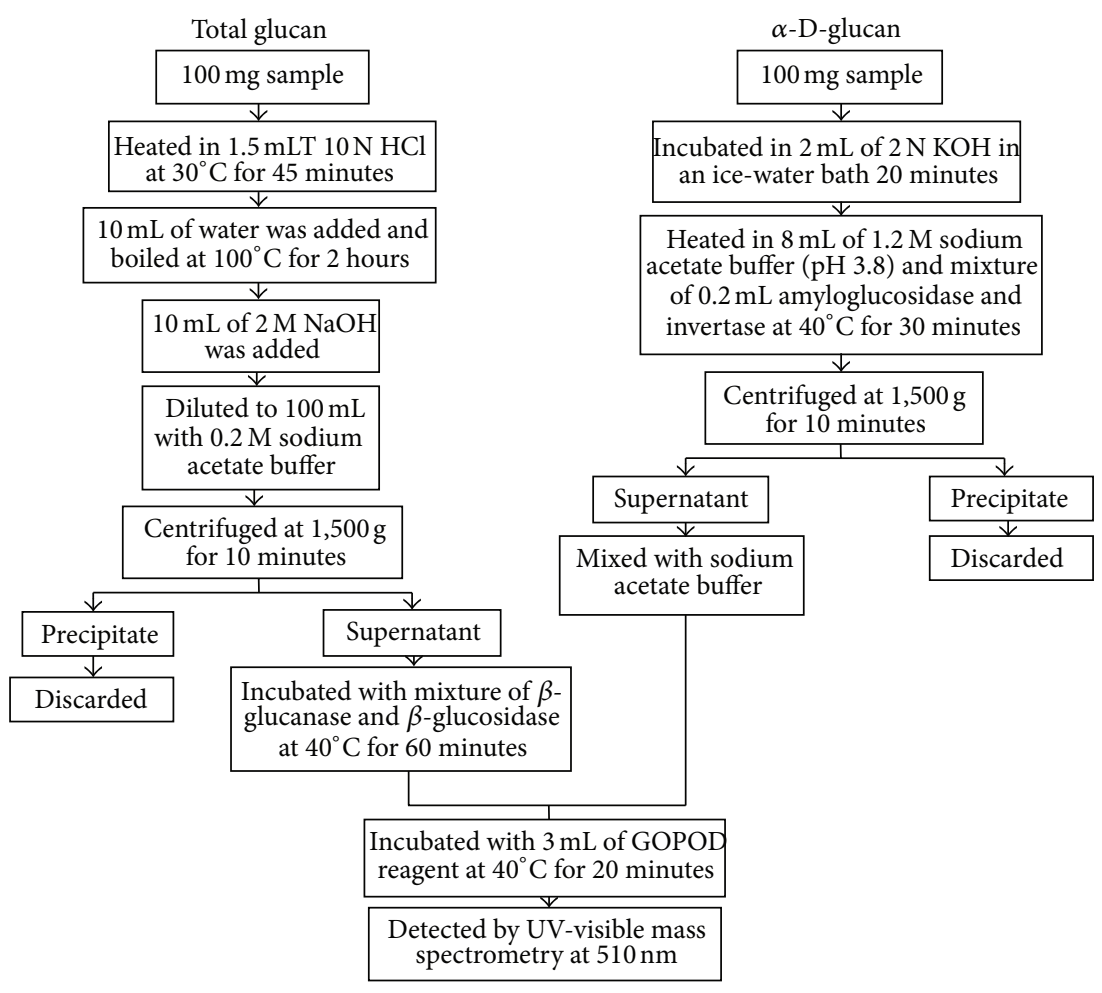

FIgURE 1: Determination of total $\beta$-D-glucan content in mushrooms.

consumed as dietary supplements $[8,12]$. Hot water, alkaline solution, and polyethylene glycol were types of solvents that have been used in the isolation of Lentinan from mushrooms [12].

In this study, the isolation of Lentinan-like $\beta$-D-glucan from Tiger's Milk Mushroom (Lignosus rhinocerus), Termite Mushroom (Termitomyces heimii), and selected local market mushrooms, namely, Button Mushroom (Agaricus bisporus), Shiitake Mushroom (Lentinus edodes), and Oyster Mushroom (Pleurotus ostreatus), has been done by using hot water and alkaline solution $(1.25 \mathrm{M} \mathrm{NaOH})$. The Lentinanlike $\beta$-D-glucan content was analyzed through mass spectrometry approach by using Liquid Chromatography Mass Spectrometry-Quadrupole Time of Flight (LCMS-QTOF).

\section{Materials and Methods}

2.1. Chemicals. Lentinan standard of Lentinus edodes was purchased from CarboMer Incorporation. Megazyme reagent kit was purchased from Merck. HPLC grade solvents were purchased from Fisher Scientific.

2.2. Plant Materials. Tiger's Milk Mushroom (Lignosus rhinoceros) and Termite Mushroom (Termitomyces heimii) were collected from Pahang and Negeri Sembilan, respectively. Button Mushroom (Agaricus bisporus), Shiitake Mushroom (Lentinus edodes), and Oyster Mushroom (Pleurotus ostreatus) were obtained from Selangor Hypermarket.
2.3. Samples Preparation. All the collected mushrooms were cleaned under running tap water. The cap area was cut into small pieces and oven-dried at $40^{\circ} \mathrm{C}$. The dried samples were homogenized with Cyclone Mill and kept at $-20^{\circ} \mathrm{C}$ until further use.

2.4. Determination of Total $\beta$-D-Glucan Content. $\beta$-DGlucan content was detected by measuring the total polysaccharide glucan and $\alpha$-D-glucan content as per Megazyme assay method (Figure 1). $100 \mathrm{mg}$ of dried powder fruit body of each sample was heated in $1.5 \mathrm{~mL}$ of concentrated hydrochloric acid $(37 \% ; 10 \mathrm{~N})$ at $30^{\circ} \mathrm{C}$ for 45 minutes. $10 \mathrm{~mL}$ of water was added and the mixture was boiled at $100^{\circ} \mathrm{C}$ for 2 hours. $10 \mathrm{~mL}$ of $2 \mathrm{M}$ potassium hydroxide was added once the mixture cooled, followed by addition of $0.2 \mathrm{M}$ sodium acetate buffer (pH 5.0) up to $100 \mathrm{~mL}$. The solution was centrifuged at $1,500 \mathrm{~g}$ for 10 minutes. $0.1 \mathrm{~mL}$ of the supernatant was taken out and heated with $0.1 \mathrm{~mL}$ of highly purified enzyme A (exo-1,3- $\beta$ glucanase $+\beta$-glucosidase) at $40^{\circ} \mathrm{C}$ for 60 minutes to obtain the total polysaccharide glucan. In separated process, $\alpha$-Dglucan was extracted by soaking the mushroom fruit body for 20 minutes in $2 \mathrm{~mL} \mathrm{KOH} \mathrm{(2N)} \mathrm{located} \mathrm{in} \mathrm{ice} \mathrm{water} \mathrm{bath.} 8 \mathrm{~mL}$ of 1.2 M sodium acetate buffer ( $\mathrm{pH} 3.8$ ) and $0.2 \mathrm{~mL}$ of Enzyme $\mathrm{B}$ (amyloglucosidase + invertase) were added immediately and incubated at $40^{\circ} \mathrm{C}$ for 30 minutes. The solution was centrifuged at $1500 \mathrm{~g}$ for 10 minutes. $0.1 \mathrm{~mL}$ of supernatant was mixed into $0.1 \mathrm{~mL}$ of sodium acetate buffer $(200 \mathrm{mM}, \mathrm{pH}$ 5.0) to obtain $\alpha$-D-glucan. 


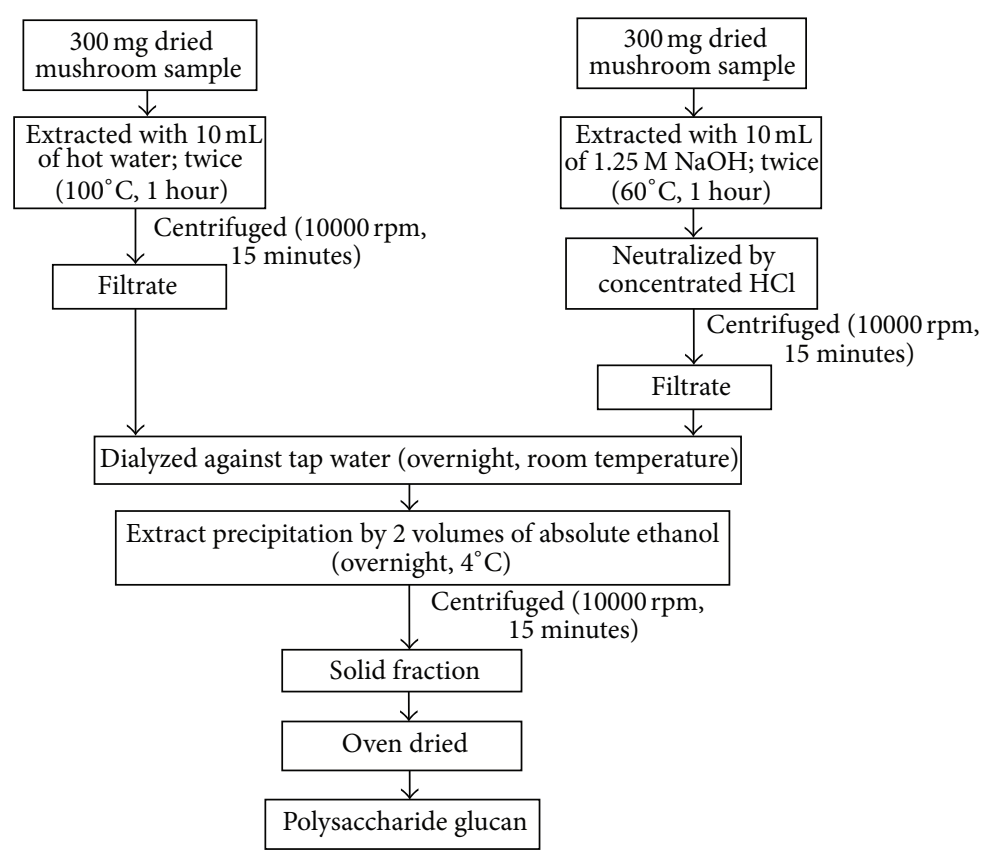

FIGURE 2: Isolation of polysaccharide glucan (Lentinan-like $\beta$-D-glucan) by hot water and alkaline solution (1.25 M NaOH).

Both total polysaccharide glucan and $\alpha$-D-glucan were heated, respectively, in $3 \mathrm{~mL}$ of GOPOD reagent at $40^{\circ} \mathrm{C}$ for 20 minutes. The concentration of total polysaccharide glucan and $\alpha$-D-glucan was determined by UV-visible mass spectrometry at $510 \mathrm{~nm}$ against reagent blank $(0.2 \mathrm{~mL}$ of $0.2 \mathrm{M}$ sodium acetate).

* Reagent blank and D-glucose standard $(0.1 \mathrm{~mL}$ of $1 \mathrm{mg} / \mathrm{mL} \mathrm{D}$-glucose standard $+0.1 \mathrm{~mL}$ of $0.2 \mathrm{M}$ sodium acetate buffer) were also heated with $3 \mathrm{~mL}$ of GOPOD at $40^{\circ} \mathrm{C}$ for 20 minutes:

$$
\begin{aligned}
& \% \beta \text {-D-glucan } \\
& =\frac{\text { Total polysaccharide glucan }-\alpha \text {-D-glucan }}{\text { Total polysaccharide glucan }} \times 100 \% \text {. }
\end{aligned}
$$

\subsection{Determination of Lentinan-Like $\beta$-D-Glucan}

2.5.1. Isolation of Polysaccharide Glucan. Polysaccharide glucan was isolated by hot water and alkaline solution $(1.25 \mathrm{M}$ Sodium hydroxide), respectively (Figure 2). $300 \mathrm{mg}$ of dried fruit body powder was extracted twice with $10 \mathrm{~mL}$ of distilled water at $100^{\circ} \mathrm{C}$ for one hour. Separately, the same amount of dried fruit body powder was extracted twice with $10 \mathrm{~mL}$ of $1.25 \mathrm{M} \mathrm{NaOH}$ at $60^{\circ} \mathrm{C}$ for one hour. Alkaline extract was then neutralized by hydrochloric acid $(\mathrm{HCl})$. Both hot water and alkaline extracts were centrifuged at 10,000 rpm for 15 minutes. The supernatants from both extracts were dialyzed against distilled water in shaking condition for overnight to remove low molecular weight substances. Two volumes of absolute ethanol were added to the hot water and alkaline extracts. Both extracts were left overnight at $4^{\circ} \mathrm{C}$ for complete precipitation. The solid fractions known as polysaccharide glucan were collected by centrifugation at $10000 \mathrm{rpm}$ for
15 minutes and oven-dried at $60^{\circ} \mathrm{C}$. The weight of dried polysaccharide glucan was recorded.

\subsubsection{LCMS-QTOF Analysis of Lentinan-Like $\beta$-D-Glucan}

Sample Preparation. $5 \mathrm{mg}$ of isolated polysaccharide glucan from hot water and alkaline extracts was dissolved with $0.5 \mathrm{~mL}$ and $1.0 \mathrm{~mL}$ of distilled water, respectively, for four hours at $90^{\circ} \mathrm{C}$. The solutions were centrifuged at 13,000 rpm for 10 minutes. The supernatants were filtered through $0.45 \mu \mathrm{m}$ syringe filter into separated HPLC vials.

Determination of Lentinan-Like $\beta$-D-Glucans. Analysis was performed by using an Agilent 1200 series Rapid Resolution Liquid Chromatography (RRLC) equipped with autosampler and diode array detection (DAD) system. An Agilent 6530 Accurate Mass QTOF was used to obtain the MS and MS/MS data. The mobile phases used were highly purified water $+0.1 \%$ formic acid (A) and acetonitrile $+0.1 \%$ formic acid (B). Column used was $4.6 \mathrm{~mm} \times 100 \mathrm{~mm}$ ThermoCarbon column. The flow rate was set up at $0.6 \mathrm{~mL} / \mathrm{min}$ with 22 minutes total run time. The column temperature was at $40^{\circ} \mathrm{C}$. The prepared samples were placed into the LCMS autosampler. The injection volume of sample was $10 \mu \mathrm{L}$. The samples were run at gradient $5 \% \mathrm{~B}(0-0.5 \mathrm{~min})$; $30 \%$ B (0.5-13 min); and 95\% B (13-22.0 min). Analysis was performed in negative ion mode with the following settings:capillary voltage: $3500 \mathrm{~V}$; nozzle voltage: $1000 \mathrm{~V}$; fragmentor voltage: $175 \mathrm{~V}$; nebulizer pressure $\left(\mathrm{N}_{2}\right)$ : 35 psi; drying gas: $5 \mathrm{~L} / \mathrm{min}$ at $350^{\circ} \mathrm{C}$, and sheath gas: $11 \mathrm{~L} / \mathrm{min}$ at $350^{\circ} \mathrm{C}$. The mass range was at $110-2000 \mathrm{~m} / z$.

Lentinan standard was prepared at $1 \mathrm{mg} / \mathrm{mL}$ by dissolving in distilled water at $90^{\circ} \mathrm{C}$ for 4 hours. Fragmentation pattern of molecular mass, elution time, and molecular weight of 


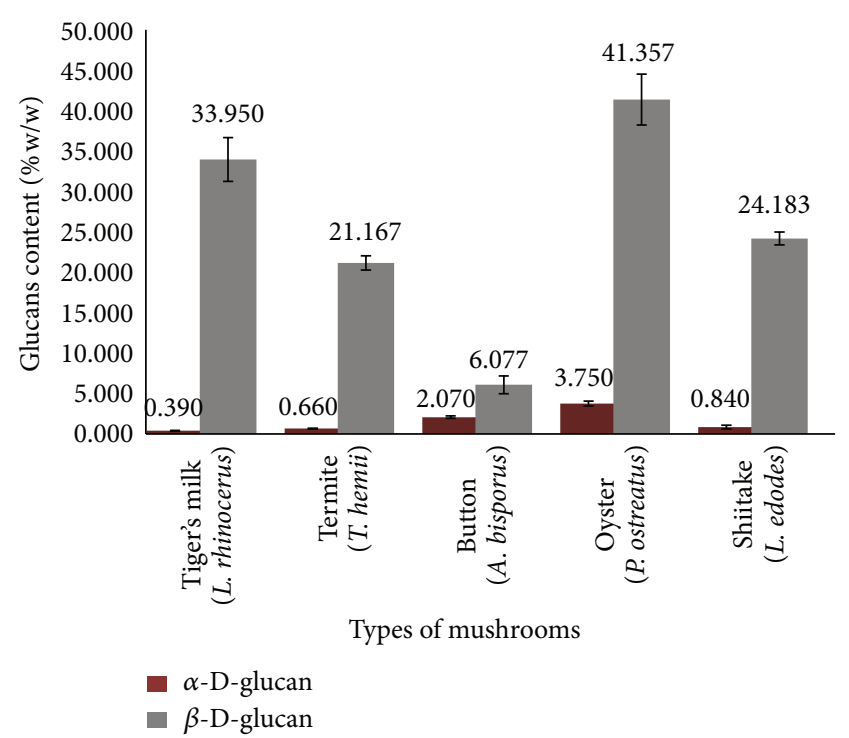

FIgUre 3: Composition of $\alpha$-D-glucan and $\beta$-D-glucan contents $(\% \mathrm{w} / \mathrm{w})$ in Tiger's Milk, Termite, Button, Shiitake and Oyster Mushrooms.

the Lentinan standard were used to analyze the presence of targeted compound. The profile patterns of total ion chromatogram (TIC) and the extracted ion chromatogram (EIC) of the extracts were recorded. A standard calibration curve of Lentinan was built to determine the Lentinan-like $\beta$-D-glucan content in the 5 types of mushrooms.

\section{Results and Discussion}

3.1. Determination of Total $\beta$-D-Glucan Content. The concentration of $\beta$-D-glucan in Tiger's Milk Mushroom (Lignosus rhinoceros), Termite Mushroom (Termitomyces heimii), Button Mushroom (Agaricus bisporus), Shiitake Mushroom (Lentinus edodes), and Oyster Mushroom (Pleurotus ostreatus) was determined by using UV-Visible Spectrophotometer. Figure 3 showed the results of total $\beta$-D-glucan contents (\% $\mathrm{w} / \mathrm{w})$ in the five selected mushrooms:

Total $\beta$-D-glucan (\%)

$$
=\frac{\text { Total polysaccharide glucan }- \text { total } \alpha-\mathrm{D} \text {-glucan }}{\text { Total polysaccharide glucan }} \times 100 \% \text {. }
$$

From the graph, it is shown that more than $50 \%$ of total polysaccharide glucan content in the mushroom fruit bodies was comprised of $\beta$-D-glucan. Oyster Mushroom showed the highest $\beta$-D-glucan content with $41.357 \%$ w/w as compared to other four mushrooms, followed by Tiger's Milk Mushroom and Shiitake Mushroom with $33.950 \% \mathrm{w} / \mathrm{w}$ and $24.183 \% \mathrm{w} / \mathrm{w}$ $\beta$-D-glucan, respectively. Termite Mushroom was found to have $21.167 \% \mathrm{w} / \mathrm{w} \beta$-D-glucan. Button Mushroom showed the least $\beta$-D-glucan content with $6.077 \% \mathrm{w} / \mathrm{w}$.

3.2. LC-QTOF Analysis of Lentinan-Like $\beta-D-G l u c a n$. As shown in Figure 4, more yield of isolated polysaccharide

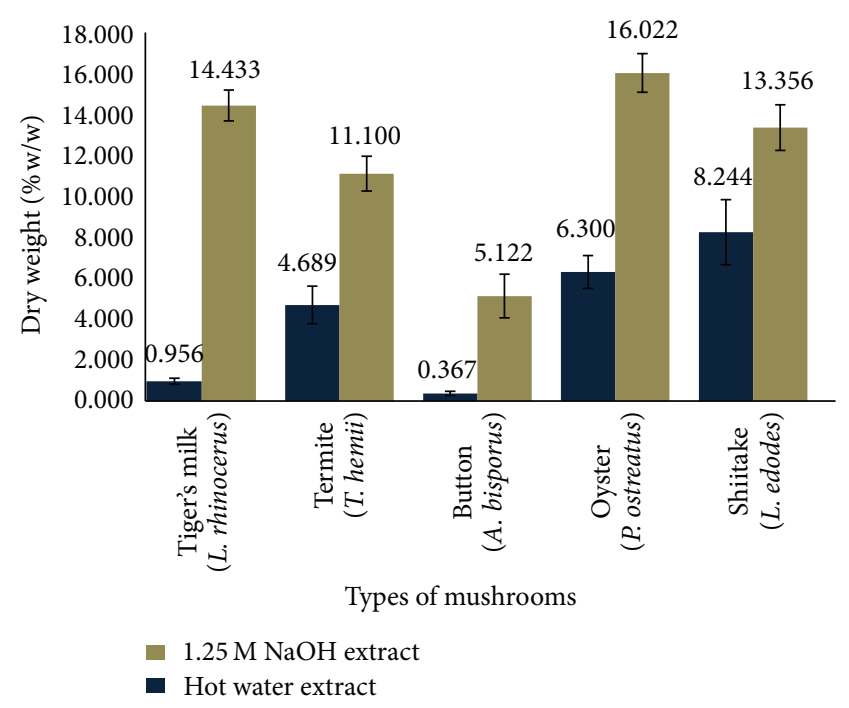

Figure 4: Dry weight of isolated polysaccharide glucan (\% w/w) in Tiger's Milk, Termite, Shiitake and Oyster Mushrooms extracted by hot water and alkaline solution $(1.25 \mathrm{M} \mathrm{NaOH})$.

glucan is obtained through $1.25 \mathrm{M} \mathrm{NaOH}$ as compared to the hot water extract. Hot water extraction is the normal procedure in the isolation of polysaccharide glucan. However, alkaline solution has been determined to have ability in improving the isolation yields of the compound [12-14]. The ratio of polysaccharide glucan in alkaline extract to the hot water extract was 14:1 for Tiger's Milk Mushroom, 11:4 for Termite Mushroom, 16:6 for Oyster Mushroom, 13:8 for Shiitake Mushroom, and 5:0.4 for Button Mushroom.

LQMS-TOF was used to detect the presence of Lentinanlike $\beta$-D-glucan in the hot water and alkaline extracts. A commercial Lentinan standard isolated from Lentinus edodes was used in this analysis. The data of molecular weight, retention time, and fragmentation pattern of the Lentinan standard obtained by negative mode MSMS were used as reference (Figure 5).

The results of total ion chromatogram (TIC) of polysaccharide glucan isolated by hot water and alkaline solution were totally different (Figure 6). From the extracted ion chromatogram (EIC) data of hot water extract there was a peak eluted at minutes 9. Molecular weight analysis on that peak exposed the presence of 1152 Dalton of $\beta$-D-glucan (Figure 7). Comparison of the fragmentation patterns between Lentinan standard (Figure 5) and the 1152 Dalton $\beta$-D-glucan (which is not shown here) showed that the Lentinan-like $\beta$-D-glucan brought the same ion fragments as Lentinan of Lentinus edodes. These suggested the presence of Lentinan-like $\beta$ $\mathrm{D}$-glucan in all the five mushrooms. However, the alkaline solution extract expressed no peak eluted at that specific time. This was due to the structure alteration of $\beta$-D-glucan as well as Lentinan in alkaline solution as $\beta$-D-glucan structure could undergo conformational change when dissolved in different solvents $[7,12]$.

3.3. Determination of Lentinan-Like $\beta$-D-Glucan Content. The concentrations of Lentinan-like $\beta$-D-glucan in the 

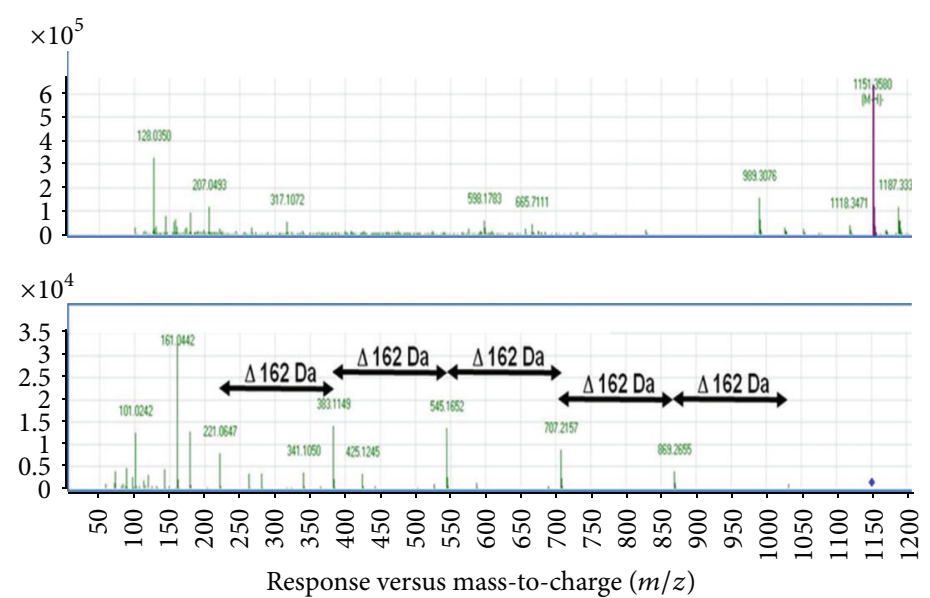

(a)
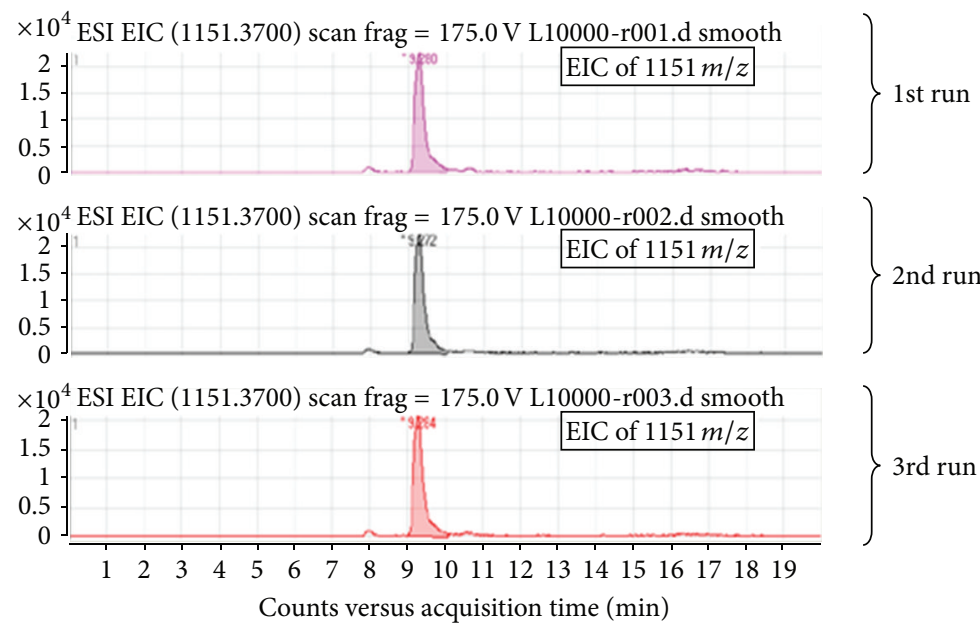

(b)

FIGURE 5: LCMS-QTOF characteristics of Lentinan Standard in negative mode MSMS. (a) Fragmentation pattern of Lentinan Standard (C42 H72 O36 $(1151 \mathrm{~m} / \mathrm{z})$ ). (b) Molecular weight and retention time of Lentinan Standard.

TABle 1: Concentration of Lentinan-like $\beta$-D-glucan from hot water extracts of Tiger's Milk Mushroom, Termite Mushroom, Button Mushroom, Shiitake Mushroom, and Oyster Mushroom.

\begin{tabular}{lccc}
\hline Types of mushrooms & $\begin{array}{c}\text { Total isolated polysaccharide glucan } \\
(\mathrm{mg}) \text { in 300 mg sample }\end{array}$ & $\begin{array}{r}\text { Concentration of Lentinan-like } \beta \text {-D-glucan }(\mu \mathrm{g} / \mathrm{mg}) \\
\text { Per 1 mg of isolated } \\
\text { polysaccharide glucan }\end{array}$ & $\begin{array}{c}\text { Per 1 mg of fruit } \\
\text { body }\end{array}$ \\
\hline Tiger's Milk Mushroom (L. rhinocerus) & $2.87 \pm 0.45$ & $0.74 \pm 0.12$ & $0.01 \pm 0.00$ \\
Termite Mushroom (T. heimii) & $14.07 \pm 2.75$ & $0.53 \pm 0.07$ & $0.02 \pm 0.00$ \\
Button Mushroom (A. bisporus) & $1.10 \pm 0.30$ & $16.16 \pm 4.15$ & $0.06 \pm 0.00$ \\
Shiitake Mushroom (L. edodes) & $24.73 \pm 4.77$ & $0.22 \pm 0.04$ & $0.02 \pm 0.00$ \\
Oyster Mushroom (P. ostreatus) & $18.90 \pm 2.40$ & $0.10 \pm 0.01$ & $0.01 \pm 0.00$ \\
\hline
\end{tabular}

isolated polysaccharide glucan of hot water extracts were determined by using Lentinan standard calibration curve. As shown in Table 1, the isolated polysaccharide glucan of Tiger's Milk Mushroom and Termite Mushroom was found to have $0.74 \pm 0.12 \mu \mathrm{g} / \mathrm{mg}$ and $0.53 \pm 0.07 \mu \mathrm{g} / \mathrm{mg}$ Tiger's Milk Mushroom and Termite Mushroom, respectively. While
Button Mushroom contained the highest Lentinan-like $\beta$ D-glucan $(16.16 \pm 4.15 \mu \mathrm{g} / \mathrm{mg})$ among the five mushrooms, Shiitake Mushroom and Oyster Mushroom showed $0.22 \pm$ $0.04 \mu \mathrm{g} / \mathrm{mg}$ and $0.10 \pm 0.01 \mu \mathrm{g} / \mathrm{mg}$ Lentinan-like $\beta$-D-glucan, respectively. By taking into account the total amount of dried isolated polysaccharide glucan obtained (as reported in 

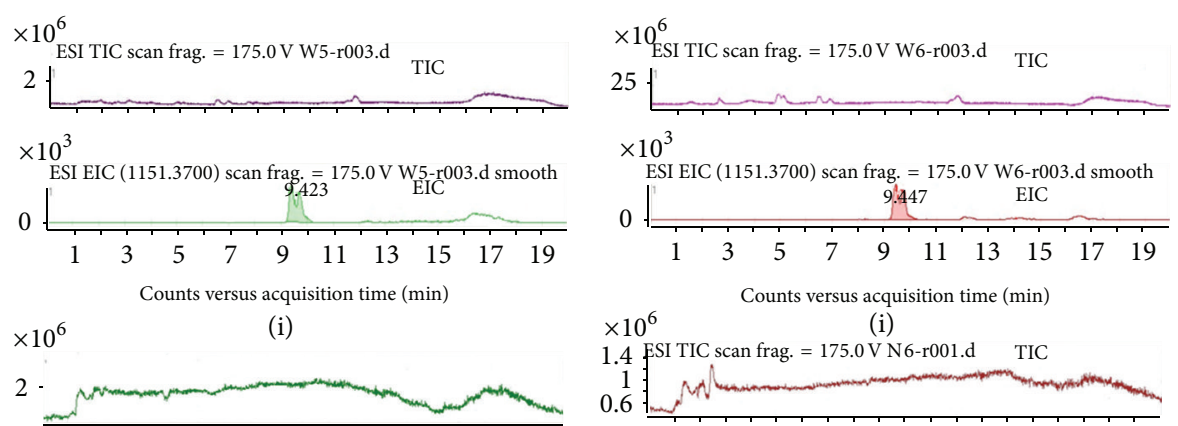

$\times 10^{6} \quad$ (i)
1.4 ESI TIC scan frag. $=175.0 \mathrm{~V} \mathrm{~N} 6-\mathrm{r} 001 . \mathrm{d} \quad$ TIC

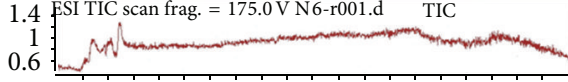

$\times 10^{3}$

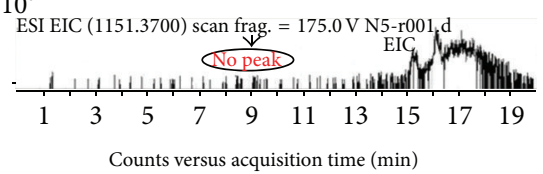

(ii)

$\times 10^{3}$

1.4 ESI EIC (1151.3700) scan frag. $=175.0$ V N6-r001.d

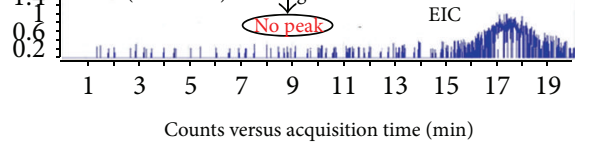

(ii)

(a)

(b)
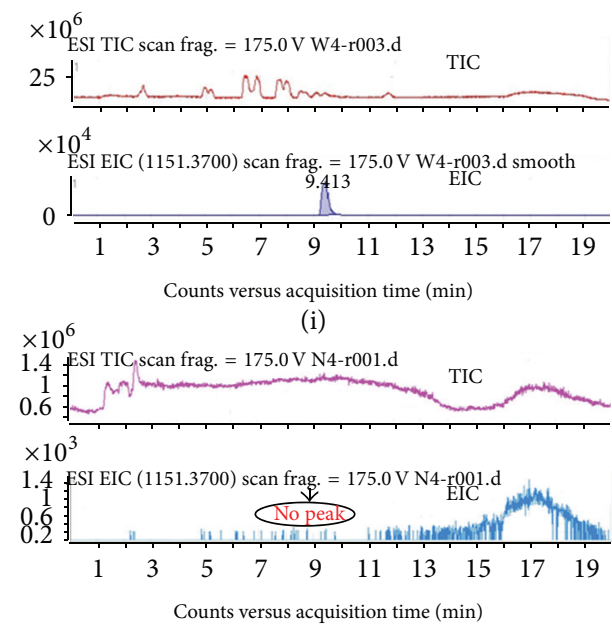

(ii)

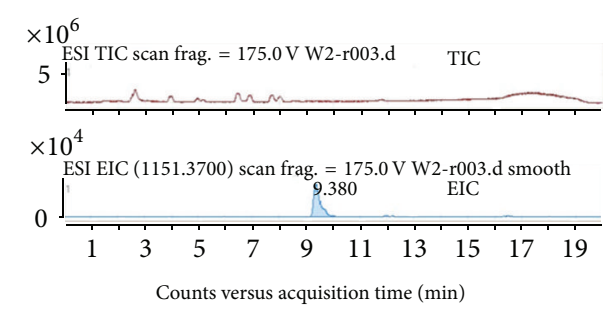

(i)

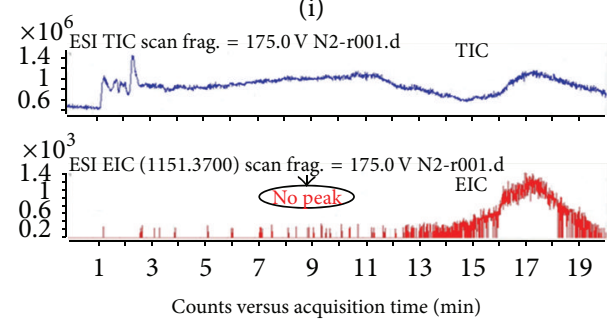

(ii)

(c)

(d)

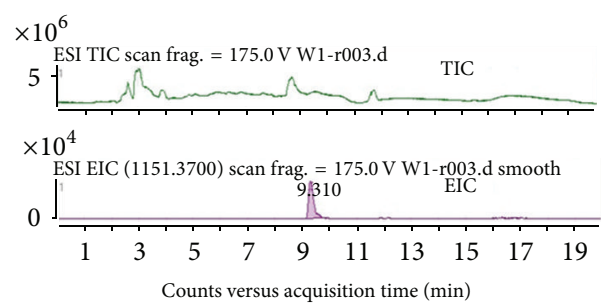

(i)

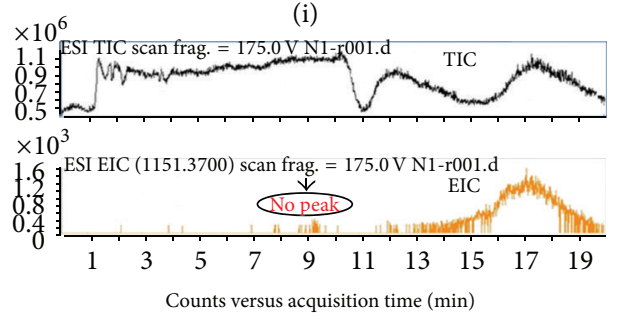

(ii)

(e)

FIGURE 6: Total ion chromatogram (TIC) of polysaccharide glucan and extracted ion chromatogram (EIC) of Lentinan-like $\beta$-glucan of (a) Tiger's Milk Mushroom; (b):Termite Mushroom; (c) Button Mushroom; (d) Shiitake Mushroom; and (e) Oyster Mushroom from isolated polysaccharide glucan of (i) hot water and (ii) alkaline solution (1.25 $\mathrm{M} \mathrm{NaOH})$. 


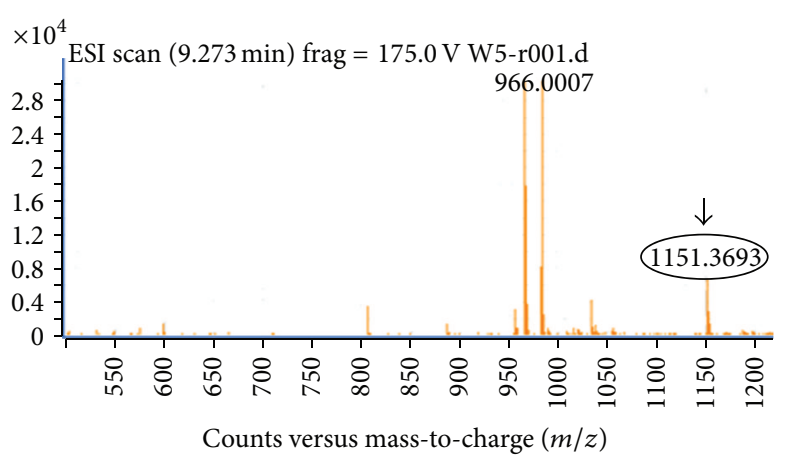

(a)

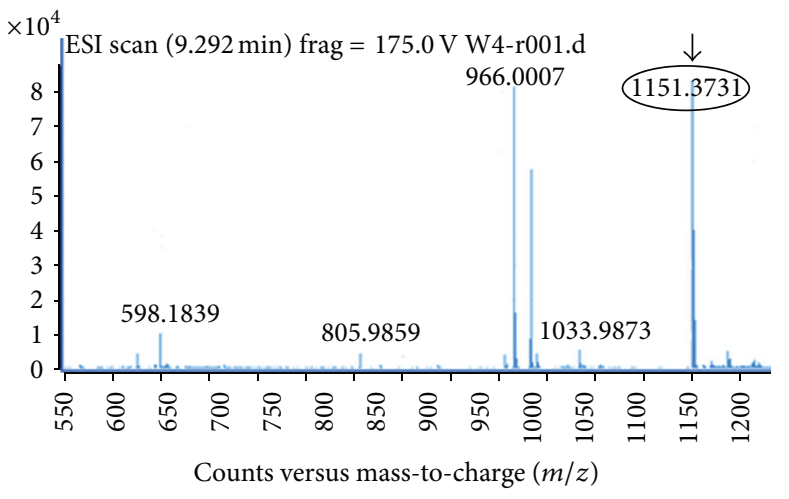

(c)

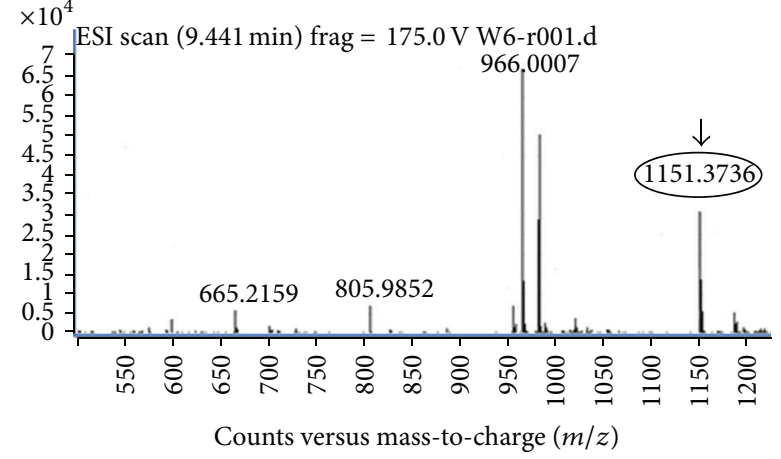

(b)

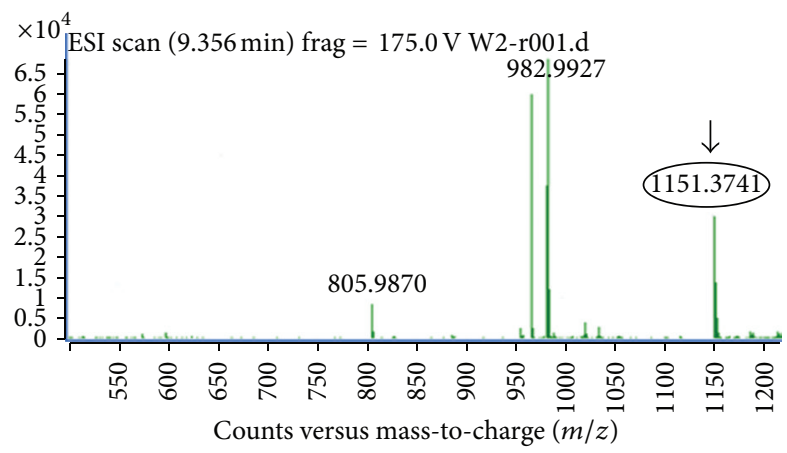

(d)

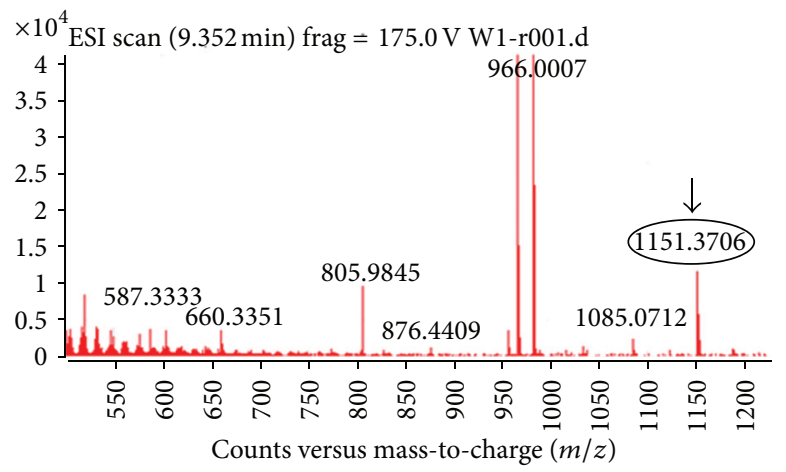

(e)

Figure 7: Determination of Lentinan-like $\beta$-D-glucan (1151 Da) in isolated polysaccharide glucan of hot water extract of 5 mushrooms (a) Tiger's Milk Mushroom; (b) Termite Mushroom; (c) Button Mushroom; (d) Shiitake Mushroom; (e) Oyster Mushroom.

Figure 1), the Lentinan-like $\beta$-D-glucan content in the whole fruit body of Tiger's Milk Mushroom and Termite Mushroom was $0.01 \pm 0.00$ and $0.02 \pm 0.00 \mu \mathrm{g} / \mathrm{mg}$, respectively. Button Mushroom was found to have $0.06 \pm 0.00 \mu \mathrm{g} / \mathrm{mg}$ Lentinanlike $\beta$-D-glucan in its fruit body. The fruit bodies of Shiitake Mushroom and Oyster Mushroom showed $0.22 \pm 0.04 \mu \mathrm{g} / \mathrm{mg}$ and $0.10 \pm 0.01 \mu \mathrm{g} / \mathrm{mg}$ Lentinan-like $\beta$-D-glucan.

\section{Conclusion}

Mushroom $\beta$-D-glucan has been targeted as an important medicinal agent as it exposes immune modulator and anticancer properties. It has been widely used as alternative medicine and dietary supplement for years. Isolation of this compound by different solutions could affect the yield of the isolated $\beta$-D-glucan extract and also its conformational state. Alkaline solution has improved the extract yield of isolated $\beta$ $\mathrm{D}$-glucan as compared to the hot water. Nevertheless, it also led to the changes in retention time of the compound as the alteration of conformational state has been occurred. These concluded that different solvents may not only affect the yield of isolated $\beta$-D-glucan but also its general structure which might divert their retention time.

\section{Acknowledgments}

The authors acknowledge Agro-Biotechnology Institute, Malaysia (ABI), and Ministry of Science, Technology and 
Innovation (MOSTI), for providing research Grant (08-05ABI PB030) to support this study. This project was financially supported by ABI R\&D Initiative Fund. There is no conflict of interests regarding this study.

\section{References}

[1] Y. S. Chang and S. S. Lee, "Utilisation of macrofungi species in Malaysia," Fungal Diversity, vol. 15, pp. 15-22, 2004.

[2] E. J. H. Corner, "Nova Hedvigia Beihefte," vol. 97, article 147, 1989, http://lignosus.wordpress.com.

[3] N. Ahmed and A. Khatwa, Termitomyces: A New Source of Potent Cellulose, J.K.A.U. Science, 1989.

[4] A. Synytsya, K. Míčková, A. Synytsya et al., "Glucans from fruit bodies of cultivated mushrooms Pleurotus ostreatus and Pleurotus eryngii: structure and potential prebiotic activity," Carbohydrate Polymers, vol. 76, no. 4, pp. 548-556, 2009.

[5] N. Abdullah, S. M. Ismail, N. Aminudin, A. S. Shuib, and B. F. Lau, "Evaluation of selected culinary-medicinal mushrooms for antioxidant and ACE inhibitory activities," Evidence-based Complementary and Alternative Medicine, vol. 2012, Article ID 464238, 12 pages, 2012.

[6] B. Srivastava, A. K. Dwivedi, and V. N. Pandey, "Morphological characterization and yield potential of Termitomyces spp. mushroom in Gorakhpur forest division," Journal of Bulletin of Environment, Pharmacology \& Life Sciences, vol. 1, no. 1, pp. 5456, 2011

[7] M. Zhang, S. W. Cui, P. C. K. Cheung, and Q. Wang, "Antitumor polysaccharides from mushrooms: a review on their isolation process, structural characteristics and antitumor activity," Trends in Food Science and Technology, vol. 18, no. 1, pp. 4-19, 2007.

[8] A. S. Daba and O. U. Ezeronye, "Anti-cancer effect of polysaccharides isolated from higher basidiomycetes mushrooms," African Journal of Biotechnology, vol. 2, no. 12, pp. 672-678, 2003.

[9] C. Du, K. O. Arnab, and S. I. Syed, "NMR and MALDI-TOF analysis of a water-soluble glucan from an edible mushroom," Volvariella Diplasia Carbohydrate Research, vol. 343, no. 16, pp. 2834-2840, 2008.

[10] L. Celine and M. Philippe, "New developments and prospective applications for beta $(1,3)$ glucans," Recent patents on biotechnology, vol. 1, no. 1, pp. 59-73, 2006.

[11] J. Chen and R. Seviour, "Medicinal importance of fungal $\beta-(1 / 3)$, (1/6)-glucans," Mycological Research, vol. 111, no. 6, pp. 635-652, 2007.

[12] Y. Zhang, S. Li, X. Wang, L. Zhang, and P. C. K. Cheung, "Advances in lentinan: isolation, structure, chain conformation and bioactivities," Food Hydrocolloids, vol. 25, no. 2, pp. 196-206, 2011.

[13] Megazyme International Ireland Limited, "Mushroom and yeast $\beta$-glucan assay procedure," 2011, http://www.libiosfr/tzr/ scripts/downloader2.php?filename=PRODUITS/notice/a6/68/ FR.4dznwqwpg2p3\&mime $=$ application $/$ pdf\&originalname $=$ KYBGL.pdf\&moid=31.

[14] X. Wang, Y. Zhang, L. Zhang, and Y. Ding, "Multiple conformation transitions of triple helical lentinan in DMSO/water by microcalorimetry," Journal of Physical Chemistry B, vol. 113, no. 29, pp. 9915-9923, 2009. 

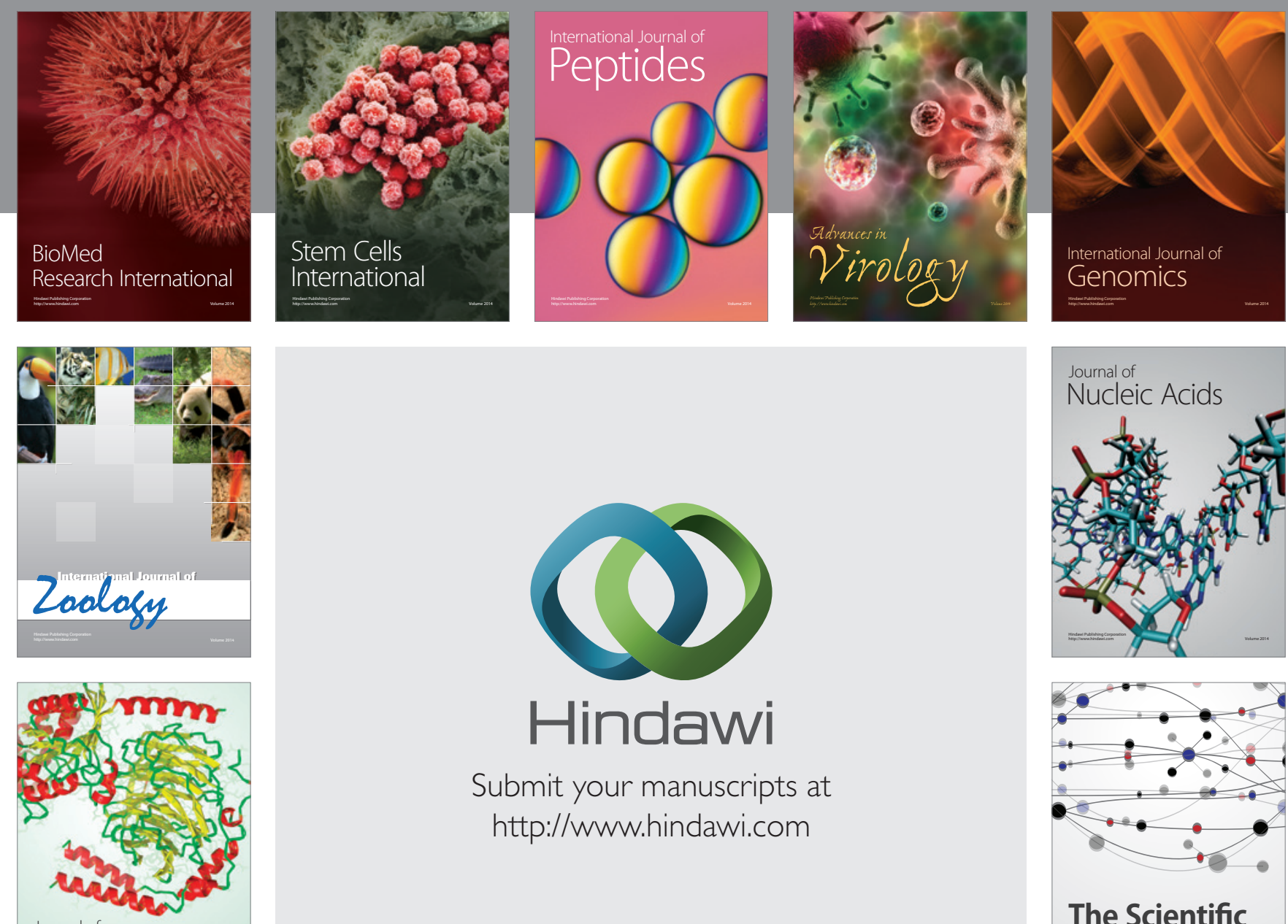

Submit your manuscripts at

http://www.hindawi.com

Journal of
Signal Transduction
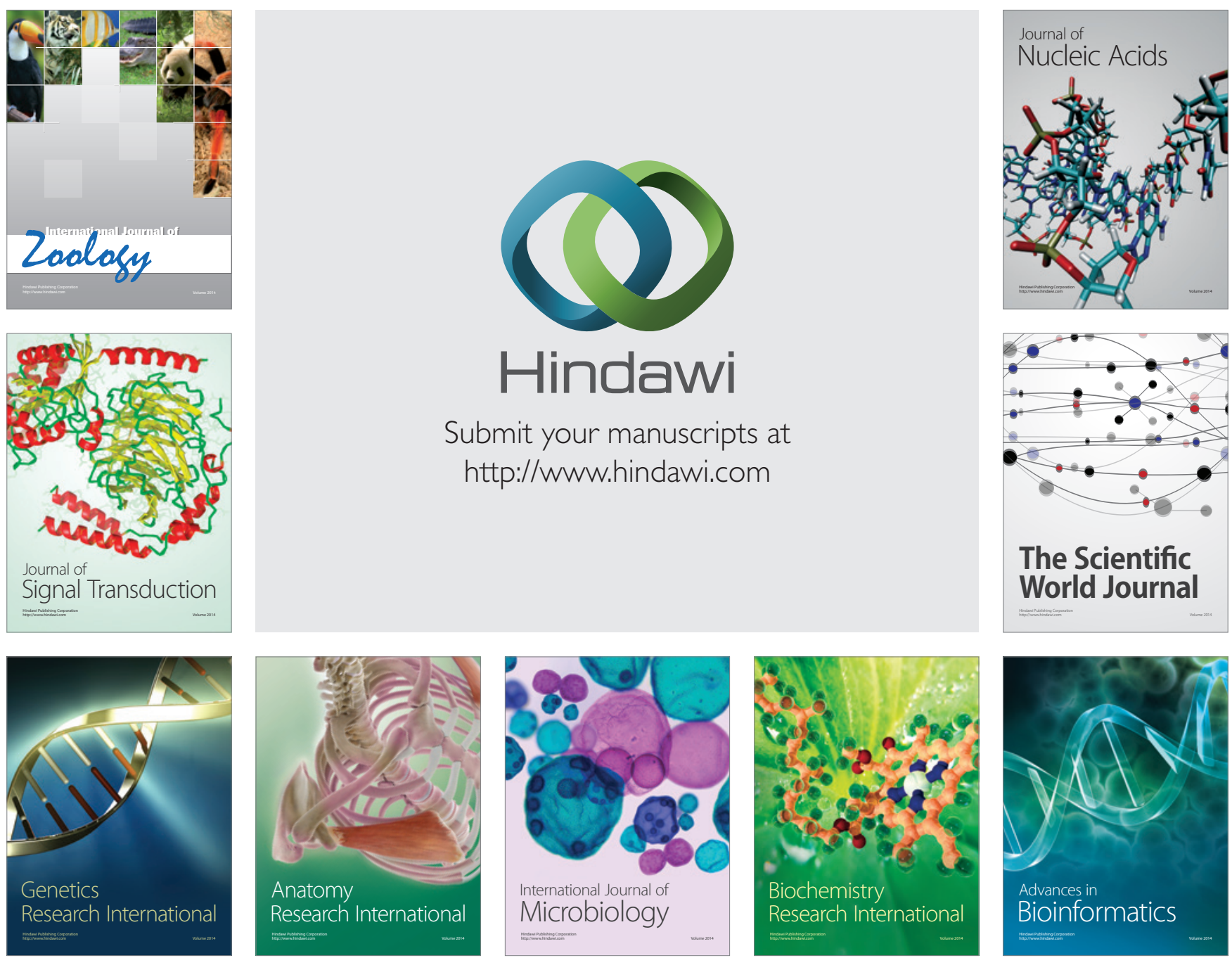

The Scientific World Journal
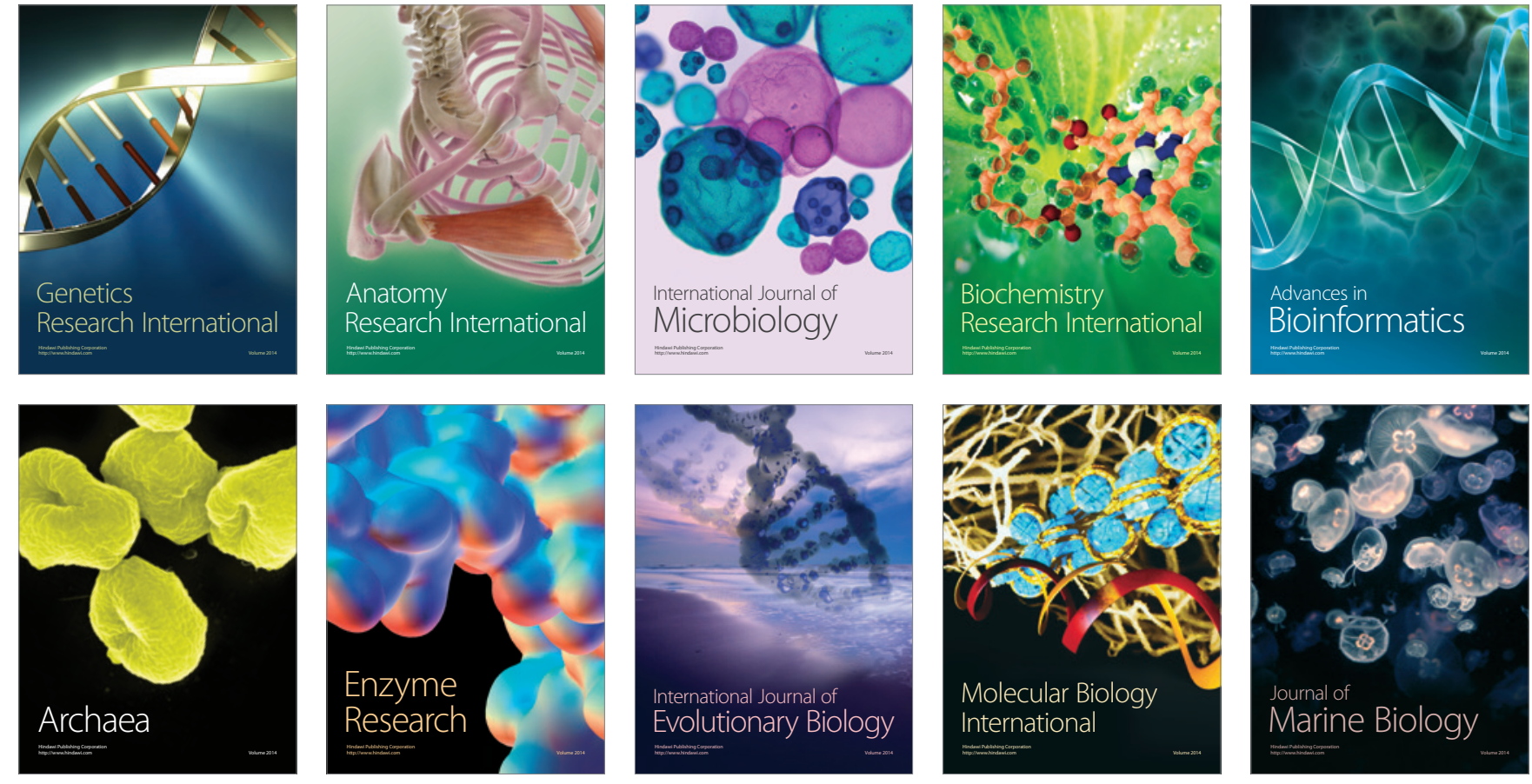